\title{
A INSPIRAÇÃO NOS TRABALHOS "DOS GRANDES CENTROS DE ESTUDOS PEDAGÓGICOS": CONSIDERAÇÕES SOBRE AS CLASSES INTEGRAIS DO COLÉGIO ESTADUAL DO PARANÁ (1960-1967)
}

DOI: http://dx.doi.org/10.1590/2236-3459/80457

\author{
Sergio Roberto Chaves Junior' \\ 'Universidade Federal do Paraná (UFPR), Curitiba/PR, Brasil
}

$\cos 8$

\begin{abstract}
Resumo
Este texto apresenta considerações sobre as Classes Integrais do Colégio Estadual do Paraná, proposta de inovação pedagógica desenvolvida entre 1960 e 1967 na modelar instituição de ensino secundário localizada em Curitiba, Paraná. São explicitadas questões específicas relacionadas ao processo de elaboração do Plano de Organização da inovação educacional, com destaque às inspirações nos "grandes centros de estudos pedagógicos". Foi possível perceber que o estudo das experiências realizadas em outras instituições de ensino possibilitou aos elaboradores do plano das Classes Integrais dar contornos a uma proposta singular em meio ao contexto das inovações educacionais no ensino secundário engendradas no Brasil nos anos 1950 e 1960.

Palavras-chave: classes integrais, ensino secundário, inovações pedagógicas, Colégio Estadual do Paraná.
\end{abstract}

\section{LA INSPIRACIÓN EN LOS TRABAJOS "DE LOS GRANDES CENTROS DE ESTUDIOS PEDAGÓGICOS": CONSIDERACIONES SOBRE LAS CLASES INTEGRALES DEL COLÉGIO ESTADUAL DO PARANÁ (1960-1967)}

\begin{abstract}
Resumen
Este texto presenta consideraciones sobre las Clases Integrales del Colegio Estadual do Paraná, propuesta de innovación pedagógica desarrollada entre 1960 y 1967 en la modelar institución de enseñanza secundaria ubicada en Curitiba, Paraná. Se explicitan cuestiones específicas relacionadas al proceso de elaboración del Plan de Organización de la innovación pedagógica, con destaque a las inspiraciones en los "grandes centros de estudios pedagógicos". Es posible percibir que el estudio de las experiencias realizadas en otras instituciones de enseñanza posibilitó a los elaboradores del plan de las Clases Integrales dar contornos a una propuesta singular en el contexto de las innovaciones educativas en la enseñanza secundaria engendradas en Brasil en los años 1950 y 1960.

Palabras clave: clases integrales, enseñanza secundaria, innovaciones pedagógicas, Colégio Estadual do Paraná.
\end{abstract}




\title{
INSPIRATION IN THE WORKS OF "THE GREAT CENTERS OF PEDAGOGICAL STUDIES": CONSIDERATIONS ABOUT THE CLASSES INTEGRAIS DO COLÉGIO ESTADUAL DO PARANÁ (1960-1967)
}

\begin{abstract}
This text presents considerations about the Classes Integrais of Colégio Estadual do Paraná, a proposal of pedagogical innovation developed between 1960 and 1967 in the modeling secondary school located in Curitiba, Paraná. Specific issues related to the process of elaborating the plan of educational innovation are highlighted, with emphasis on inspiration in the "great centers of pedagogical studies". It was possible to notice that the study of the experiences carried out in other secondary schools allowed the elaborators of the plan of the Classes Integrais to outline a singular proposal in the context of the educational innovations in secondary education engendered in Brazil in the 1950s and 1960s.

Keywords: integral classes, high school, pedagogical innovations, Colégio Estadual do Paraná.
\end{abstract}

\section{INSPIRATION DANS LES TRAVAUX DES "GRANDS CENTRES D'ÉTUDES PÉDAGOGIQUES": CONSIDÉRATIONS SUR LES CLASSES INTEGRAIS DO COLÉGIO ESTADUAL DO PARANÁ (1960-1967)}

\section{Résumé}

Ce texte présente des considérations sur les classes intégrales du Colégio Estadual do Paraná, une proposition d'innovation pédagogique développée entre les années de 1960 et 1967 dans le établissement d'enseignement secondaire modèle situé à Curitiba, Paraná. Les questions spécifiques liées au processus d'élaboration du Plan d'organisation de l'innovation pédagogique sont soulignées, misée en évidence l'inspiration dans les " grands centres d'études pédagogiques». C'était possible constater que l'étude des expériences menées dans d'autres institutions éducatives a permis aux élaborateurs du plan des classes intégrales de donner forme à une proposition singulière au milieu des innovations éducatives dans l'enseignement secondaire engendrées au Brésil dans les années 1950 et 1960.

Mots-clés: classes intégrales, enseignement secondaire, innovations pédagogiques, Colégio Estadual do Paraná. 


\section{Palavras iniciais}

$\mathrm{N}$

este texto são apresentadas questões que envolvem a elaboração do "Plano de Organização" das Classes Integrais do Colégio Estadual do Paraná $(C E P)^{1}$, uma proposta de inovação pedagógica do ensino secundário desenvolvida no recorte temporal compreendido entre 1960, com o ingresso das primeiras turmas para o curso ginasial ${ }^{2}$ e o ano letivo de 1967, que marcou o último registro de funcionamento da iniciativa. A realização dessa experiência pedagógica e das congêneres desenvolvidas em outras instituições de ensino brasileiras, com recortes temporais aproximados e que na maior parte das vezes foram denominadas Classes Experimentais $^{3}$, constituiu parte das propostas de inovações pedagógicas do ensino secundário engendradas a partir dos anos 1950 em território nacional.

Com o intento de localizar as relações estabelecidas entre as Classes Integrais do CEP e as demais inovações pedagógicas do ensino secundário desenvolvidas no Brasil nos anos 1950 e 1960, procurei realizar uma operação metodológica levando em consideração diferentes planos de análise, ou como sugere Jacques Revel (1998), utilizando "jogos de escalas". Tal operação se mostrou profícua, pois além de atribuir a um fenômeno específico comportamentos "globais e médios", também tornou possível "explicar a lógica da significação dessas experiências em sua singularidade”. (REVEL, 1998, p. 12).

\footnotetext{
${ }^{1}$ A despeito de algumas interpretações que consideram o CEP a instituição de ensino secundário mais antiga do estado do Paraná, tendo sua "origem" no Licêo de Coritiba, fundado em 1846, preocupo-me em circunscrever a investigação atentando para um momento histórico muito particular da instituição. Em meados da década de 1940 foi iniciada a construção da atual sede do educandário, sendo entregue em 1950 e considerado, à época, "o maior estabelecimento de ensino secundário não só do Brasil, mas também da América do Sul". (STRAUBE, 1993). Além disso, aqueles anos coincidem com a criação da Secretaria de Estado de Educação e Cultura do Paraná, a qual designou o CEP como um órgão da secretaria e que teria como competência "servir como centro-modelo para os estabelecimentos de ensino secundário, de acordo com a legislação federal sobre o assunto". (PARANÁ, 1948). Dessa forma, é possível sugerir que aquelas décadas foram marcadas pela intensificação de discursos favoráveis às reformas do ensino secundário, somada à consolidação de relações do modelar educandário paranaense com outras instituições - como a Secretaria de Educação e Cultura e a própria Universidade do Paraná - e à atuação dos professores e professoras protagonizada nestes espaços, o que contribuiu para o que CEP se constituísse como cenário para a realização de um conjunto de iniciativas educacionais, dentre elas, as Classes Integrais do Colégio Estadual do Paraná.

2 Ensino secundário compreende uma das ramificações do nível de escolaridade imediatamente posterior ao ensino primário e que, de acordo com a legislação vigente no recorte temporal do estudo, compunha a educação de grau médio juntamente com o ensino agrícola, o industrial, o comercial e o normal. Caracterizado como propedêutico para o acesso aos estudos superiores e dirigido à formação de individualidades condutoras que assumiriam as responsabilidades maiores dentro da sociedade e da nação (BRASIL, 1952), o ensino secundário foi organizado em dois ciclos sequenciais pela Lei Orgânica do Ensino Secundário de 1942, a saber: o curso ginasial, de duração de quatro anos; e o colegial, subdividido em curso clássico e curso científico, cada um com três anos de duração. A Lei 4.024, que estabeleceu Diretrizes e Bases da Educação Nacional implementada em 1961 manteve a divisão do ensino secundário nos ciclos ginasial e colegial, oportunizando a variedade e flexibilidade de currículos para ambos. Apenas para registrar, a proposta das Classes Integrais do CEP foi desenvolvida exclusivamente no ciclo ginasial.

3 Cabe assinalar que a denominação Classes Integrais guarda relação à especificidade da proposta de inovação do CEP. Dentre os argumentos localizados nas fontes, destaca-se a adoção de nomenclatura diferenciada em virtude do horário integral de funcionamento, do "espírito de educação integral", do receio de que o nome experimental não encontrasse repercussão favorável junto aos pais e, por fim, da consciência de que não seria possível dispor, de início, das condições indispensáveis para a realização de um trabalho rigorosamente experimental. (CEP, 1960; 1967). A despeito dessas observações, ao longo do desenvolvimento do projeto as designações "Classes Integrais (Experimentais)", "Classes Experimentais (Integrais)" ou simplesmente "Classes Experimentais" aparecem com frequência em relatórios, pareceres, documentos governamentais e na imprensa como formas de se referir a essa proposta realizada. Mais informações, ver Chaves Jr. (2017).
} 
Outra chave de leitura utilizada para a análise remete às contribuições de Edoardo Grendi (1998), que caracteriza a experiência paranaense como um "excepcional normal". Esta operação possibilitou perceber quais as especificidades das Classes Integrais - dada suas particularidades e sua inserção em um contexto específico - ao mesmo tempo em que foi possível vislumbrar relações mais ampliadas, pois ela representava uma das propostas das inovações pedagógicas do ensino secundário naqueles anos. Em outras palavras, procurei destacar o que havia de "excepcional" na experiência desenvolvida no CEP e que se articulou com o "normal" do contexto e das inovações pedagógicas coetâneas.

Os meados do XX foram marcados pelo "imperativo da renovação", conforme ponderou Rosa Fátima de Souza (2008), com a intensificação do debate acerca da necessidade da expansão e, sobretudo, da transformação do ensino secundário. Com isso, a aposta nas inovações educacionais foi uma das alternativas elegidas, sendo possível identificar o incremento da circulação de ideias e modelos pedagógicos ancorados no que podemos chamar ideário experimentador. Esse ideário foi constituído por dois elementos principais, entrecruzados: o primeiro, como sinônimo de experiência científica controlada, podendo ser mensurado por meio dos procedimentos de observação, registro e verificação próprios do campo científico, procurando conferir legitimidade às propostas educacionais. O segundo elemento estava associado à ideia de inovação, compreendendo-a como a possibilidade, no campo educacional, de "introduzir mudanças num objeto, visando produzir melhorias", embora desenvolvida sobre as bases da "escola tradicional"4.

No caso específico da modelar instituição de ensino secundário localizada em Curitiba, Paraná, a implementação das Classes Integrais foi motivada, inicialmente, pela identificação de dois problemas de ordem cotidiana do CEP: os elevados índices de reprovação e de evasão escolar. Em 1958, uma pesquisa realizada pela direção do colégio identificou que era "insignificante [a] percentagem de alunos que chegavam a concluir a $4^{a}$ série ginasial" no educandário paranaense, especialmente nas turmas masculinas do período matutino. (CEP, 1963). O então diretor do CEP, Ulysses de Mello e Silva, solicitou a um conjunto de professores ${ }^{5}$ a elaboração de um plano de ação que pudesse resolver a questão dos altos índices de evasão e repetência, e, aproveitando a oportunidade, também investisse na flexibilização curricular e no ensaio de novos métodos pedagógicos conforme previsto nas orientações para a instalação das Classes Experimentais. Segundo ele, "o Colégio Estadual do Paraná com a tradição que possui, com excelentes condições materiais e corpo docente de elevado gabarito não podia ficar à margem desse movimento renovador no campo educacional". (ibid., p. 2).

O mapeamento de algumas inovações esparsas realizadas ao longo da década de 1950 permite considerar que o ápice do ideário experimentador foi representado pela

\footnotetext{
${ }^{4}$ Sobre essa questão, ver as análises de Celso Ferretti (1980).

${ }^{5}$ A elaboração do projeto, iniciada nos meses finais de 1959, ficou a cargo da professora Ruth Compiani, pedagoga formada pela Universidade do Paraná (UP) e que à época ministrava a disciplina Didática Especial na "seção" de Pedagogia da Faculdade de Filosofia, Ciências e Letras na mesma universidade. Juntamente com ela, integrou a equipe um conjunto de professores e professoras que já faziam parte do quadro docente do CEP e que respondiam diretamente pelas disciplinas que comporiam o currículo das Classes Integrais. O projeto também contou com a participação de outros professores da UP, como é o caso do Albano Woiski, professor de Didática Geral, e de Cecília Maria Westphalen, catedrática de História Moderna e Contemporânea. A indicação do nome da professora Ruth para coordenar as Classes Integrais muito provavelmente foi intermediada por ambos, uma vez que suas trajetórias coincidem em diversas atividades acadêmicas e pedagógicas.
} 
oficialização da proposta das Classes Experimentais ${ }^{6}$, autorizada por meio das "Instruções sobre a natureza e organização das classes experimentais", documento da Diretoria do Ensino Secundário (Dese) publicado em 1958 e que estabelecia as normas de implementação e funcionamento desse tipo de classe a partir do ano seguinte. Tal movimento foi caracterizado pelo desenvolvimento de poucas - e variadas - experiências realizadas em alguns estados brasileiros, propondo essencialmente o "ensaio de métodos pedagógicos e novos tipos de currículos" visando à formação da juventude para as tarefas e responsabilidades da vida social e profissional. (MEC, 1958).

O contexto que possibilitou o desenvolvimento de propostas como a das Classes Experimentais contou com algumas particularidades. Aquele intervalo de experiência democrática situado entre períodos ditatoriais da história brasileira (GOMES, 2013) foi marcado pelo aperfeiçoamento das estruturas institucionais responsáveis tanto pela organização e administração do sistema de ensino, quanto pelo incremento da produção e difusão de ideias que serviram para fomentar o debate acerca das reformas pretendidas, em especial, no ensino secundário. Para isso concorrem a atuação dos intelectuais que ocuparam cargos estratégicos nas diferentes instâncias administrativas e o protagonismo destes mesmos atores na circulação das concepções e proposições, em especial, por meio dos impressos pedagógicos. Tal organização institucional possibilitou investimentos em políticas de reconhecimento dos sistemas de ensino e das propostas de inovações pedagógicas desenvolvidas em outros países, em especial, Estados Unidos, França e Inglaterra e que se constituíram como referências para o cenário brasileiro.

A circulação desses atores, na condição de professores, gestores e autoridades do ensino colaborou para alimentar o debate interno com as possibilidades de reformas desenvolvidas em outros países. As particularidades dessas reformas do ensino secundário realizadas no exterior foram percebidas tanto por meio de viagens de intercâmbio e de pesquisas de educadores brasileiros, quanto pelo acesso a tradução de textos de autores estrangeiros publicados com frequência nos periódicos pedagógicos, em especial na Revista Brasileira de Estudos Pedagógicos (RBEP) e na Revista de Pedagogia da USP ${ }^{7}$. A essas duas vias (visitas in loco e traduções de textos) devemos acrescentar o trânsito de especialistas estrangeiros, principalmente sob os auspícios da Unesco, que em solo brasileiro também colaboraram para a difusão do conhecimento dos sistemas de ensino de seus países de origem.

Havia o entendimento naquele contexto de que era preciso ter cuidado em não

\footnotetext{
6 Importa considerar que, conforme defendido por Sandra Marques (1985), Ângela Tamberlini (2001), Daniel Chiozzini (2014) e Letícia Vieira (2015), existem indícios da realização de experiências inovadoras nesses moldes antes mesmo da autorização de funcionamento de âmbito nacional, em especial no estado de São Paulo contando com o protagonismo, dentre outros, do professor Luis Contier. Outra experiência de considerável impacto naquele contexto foi a desenvolvida no Colégio Nova Friburgo da Fundação Getúlio Vargas, tendo nas figuras dos professores Luiz Alves de Mattos e Irene Mello Carvalho papeis de destaque na concretização e difusão daquela proposta. Sobre o CNF, ver Pablo Santos (2005) e Irene Carvalho (1954). No próprio Colégio Estadual do Paraná, em 1957, foi desenvolvida uma iniciativa pontual denominada Colégio Experimental, analisada na sequência deste texto.

7 Periódico criado em 1955, organizado e dirigido por Onofre de Arruda Penteado Junior, professor catedrático de Didática Geral e Especial da Faculdade de Filosofia, Ciências e Letras da Universidade de São Paulo. Mais informações sobre o periódico, ver Ellen Rozante (2008). O destaque a essa revista deve-se ao fato de que foi por meio de um texto nela publicado - de autoria de Edna Chagas Cruz intitulado "Os Métodos Ativos nas Classes Experimentais do Liceu de Sèvres" - que a proposta das Classes Integrais do Colégio Estadual do Paraná teve inspirações, conforme veremos adiante.
} 
operar com a "transplantação de padrões" dos sistemas de ensino exteriores sem levar em consideração as particularidades nacionais. Anísio Teixeira chamou a atenção para essa questão ao criticar que "nosso esforço de civilização" foi constituído por um "esforço de transplantação [...] das tradições e instituições europeias, entre as quais as tradições e instituições escolares" (1953, p. 23), e que, via de regra, foram iniciativas de pouco sucesso por não observarem as "deficiências da realidade" brasileira. Somam-se a essas considerações de Anísio alguns apontamentos de Isaac Kandel ${ }^{8}$ que, em um texto traduzido e publicado na RBEP, foi enfático:

Os sistemas educacionais não são susceptíveis de transplantação de um ambiente cultural para outro. Já as ideias e os princípios podem ser modificados e fecundamente adaptados, tendo em vista seu ajustamento a novas condições. (1956, p. 31).

Além da questão da transplantação, outro importante elemento costumava ser destacado por Anísio Teixeira e outros intelectuais: ao mirar as reformas e os sistemas de ensino estrangeiros, era preciso atentar para o fato de que, nestes países tidos como referências, as reformas eram desenvolvidas para reestruturar os sistemas de ensino já instalados; a particularidade do Brasil residia no fato de que era preciso "implantar" um sistema de ensino secundário. Nessa esteira, Geraldo Bastos Silva criticou a prática sistemática da transplantação cultural, pois, para ele, "a nossa história educacional é principalmente a história de reiteradas tentativas de transplantação de ideias e instituições europeias" (1969, p. 33), com o agravante de que, ao mirar nos modelos estrangeiros e procurar a transplantação sem o "indispensável espírito crítico", sucessivos malogros ocorreram, pois não "dispúnhamos das condições objetivas, resultantes das tradições gerais e pedagógicas e do desenvolvimento econômico e social, que servissem de suporte a um funcionamento eficaz e pleno de tais instituições". (ibid., p. 34). Logo, se tornaram "inevitáveis [...] as distorções dos modelos importados, e o funcionamento das instituições transplantadas em condições insatisfatórias de eficiência”. (ibid.).

Do conjunto de iniciativas desenvolvidas nos anos 1950 procuro dar destaque a algumas que, fomentadas pelo ideário experimentador encontraram um contexto favorável para a sua realização e serviram como ensaio, como preparo para a instalação das Classes Experimentais no ensino secundário, a partir de 1959. A escolha em apresentá-las reside no fato de que alguns dos elementos presentes nessas diferentes propostas contribuíram para a elaboração do plano das Classes Integrais do CEP. É uma constante localizar nos documentos da experiência paranaense menções aos "grandes centros de estudos pedagógicos" que serviram de "inspiração" para a sua efetivação, reforçando que o "estudo das experiências" realizadas em outras instituições de ensino possibilitou aos elaboradores da proposta do CEP "confrontar pontos de vista e assegurar uma orientação dentro das mais bem fundamentadas tendências pedagógicas". (CEP, 1963, p. 3). Em uma das fontes mobilizadas, as questões do debate sobre as inovações no ensino secundário estavam

8 Isaac Leon Kandel (1881-1965) é considerado um dos pioneiros em pesquisas comparativas e internacionais. Foi consultor internacional de desenvolvimento educacional da ONU e da Unesco entre 1946 e 1962. Uma das obras de referência de Kandel é intitulada Comparative education, de 1933, a qual é revista e publicada em 1955 sob o título The new era in education: a comparative study, sendo traduzida e impressa no Brasil, em 1960, sob o título "Uma nova era em educação: estudo comparativo". A referência a essas obras e o reconhecimento de Kandel como uma autoridade no cenário educacional são localizadas com frequência no debate brasileiro. 
condensadas da seguinte forma:

Através da criação das Classes Experimentais, o Ministério da Educação e Cultura concedeu, pela primeira vez, aos educadores brasileiros, a oportunidade de tentarem modificações ao panorama do ensino médio à base de experimentações controladas. É uma iniciativa que tem merecido muitos louvores, pois até então vínhamos, apenas, transplantando sistemas educacionais estrangeiros sem nos importar muito com a nossa realidade, com o nosso tipo de aluno, com nossas condições culturais. (CEP, 1963, p. 1).

Na sequência do documento há a indicação dos "pontos de partida" para a elaboração do plano, a saber: "Colégio da Fundação Getúlio Vargas - Nova Friburgo"; Colégios de Aplicação das Faculdades de Filosofia da "Universidade de São Paulo" e da "Universidade do Rio Grande do Sul"; além das experiências estrangeiras do "Centro Internacional de Estudos Pedagógicos de Sèvres - França" e do "Liceu Manoel de Salas Chile”. (ibid., p. 3). Nas próximas laudas privilegio a identificação e análise dessas experiências e de que formas foram apropriadas na elaboração da proposta paranaense.

\section{O Colégio Nova Friburgo da Fundação Getúlio Vargas e o Método de Ensino por Unidades Didáticas}

A primeira experiência de significativo impacto para a elaboração do plano das Classes Integrais do CEP foi o Colégio Nova Friburgo (CNF) da FGV ${ }^{9}$. A constituição dessa instituição friburguense passa pelas iniciativas de reconhecimento dos sistemas de ensino estrangeiros feitos pela professora Irene Mello Carvalho, que no início da década de 1950, na condição de diretora do Departamento de Ensino da FGV, realizou um conjunto de incursões de pesquisas na Europa e nos Estados Unidos ${ }^{10}$. Das observações na França, especificamente na "École de Sèvres", apesar da boa impressão quanto à participação ativa e à disciplina dos alunos, facilitadas "pelo número reduzido de alunos por turma (9 ou 10 apenas)", Irene Carvalho teceu algumas críticas às conferências, aulas e seminários que presenciou, os quais foram "brilhantes" na forma, mas "fracos" em conteúdo onde "nada de novo" foi observado, além de destacar o "erro pedagógico grave" quanto ao emprego da "motivação negativa" adotada pelos professores na relação com os alunos. Ainda compuseram o relatório da professora as críticas à interpretação dada à disciplina "Étude du Milieu" [Estudo do Meio] a qual, na sua opinião, não estaria sendo utilizada para integrar o aluno na sociedade contemporânea ${ }^{11}$. Comentários negativos ainda foram direcionados

\footnotetext{
9 Um estudo sobre esta instituição foi realizado por Pablo dos Santos (2005), trazendo importantes elementos para a compreensão do que representou esta instituição no contexto de inovações educacionais, entre 1948, quando a instituição foi fundada - entrou em funcionamento efetivamente em 1950 -, até 1977, ano de encerramento das atividades do educandário. Atendia meninos, em regime de internato e meninas, em regime de externato. (LOPES, 1962). Com relação à fundação do CNF, também é importante dar destaque ao papel do professor Luiz Alves de Mattos, um dos idealizadores da proposta e que à época também era diretor do Colégio de Aplicação da Universidade do Brasil, o que possibilitou o intercâmbio de experiências entre os docentes das duas instituições. (SANTOS, 2005).

10 Irene Mello Carvalho teve oportunidade de realizar viagens de estudos à Europa, janeiro e fevereiro de 1952, participando de uma série de atividades em instituições de ensino secundário, principalmente (o roteiro incluiu Espanha, França e Inglaterra). Em dezembro do mesmo ano, foi para os Estados Unidos realizar observações nas instituições de ensino secundário e em universidades ianques, retornando em fevereiro de 1953. Os relatórios referentes a essas viagens encontram-se disponíveis no Núcleo de Documentação da FGV, no Rio de Janeiro. Uma versão sucinta do relatório da viagem aos Estados Unidos foi publicada na RBEP. (CARVALHO, 1953b).

11 A professora se dizia surpresa por ter presenciado, na tarde dedicada a essa cadeira, os alunos em
} 
ao museu pedagógico, à biblioteca e às exposições temáticas realizadas pelos alunos. (CARVALHO, 1952).

As observações realizadas nos Estados Unidos parecem ter despertado melhores impressões em Irene Carvalho, pois em seus relatórios sobre o conjunto de instituições públicas de ensino secundário visitadas destacou as Public High-Schools, especialmente o fato de que estas tinham como princípio a preocupação em educar "todos os adolescentes, verdadeiro ideal da democracia americana, que se preocupa com a formação da totalidade dos cidadãos, e não apenas com o preparo de um grupo de privilegiados, quer pela fortuna, quer pela inteligência". (CARVALHO, 1953b, p. 45). E continuou:

É óbvio que um sistema de ensino que procura atender a todos, com a disparidade de aptidões e capacidades que caracteriza qualquer grupo humano, apresentará falhas e deficiências que não são notadas em escolas seletivas. Por outro lado, valores sociais, que emergem de tão ampla assistência educativa, compensam fartamente, a nosso ver, tais lacunas e talvez sejam os principais responsáveis pelo progresso daquela nação e por seu alto padrão de vida. (ibid., p. 45-46).

A identificação com os "mais avançados ideais democráticos" e com o fato de as escolas norte-americanas receberem "todos os jovens de uma comunidade, oferecendoIhes um currículo variadíssimo - que permite[sse] atender às diferenças individuais" (ibid., p. 53) parece ter sido decisiva para que em diversas oportunidades os trabalhos desenvolvidos no CNF fizessem com que a alcunha "High-School no Brasil" fosse a ele atribuída, conforme localizado nos periódicos da época ${ }^{12}$. Além disso, os trabalhos em equipe, que buscavam evitar "incrementar o individualismo" e o emprego de "métodos progressistas" que oportunizavam "riqueza de experiência", ao desenvolver a "iniciativa e a autonomia de pensamento" nos alunos foram positivamente destacados e pareciam muito adequados aos intentos formativos pretendidos pelos professores da instituição de Nova Friburgo. Das inovações metodológicas observadas, é possível sugerir que a mais impactante foi o "caráter experimental" da prática pedagógica, identificada em diferentes instituições e que tinha como princípio o fato de que

nenhuma solução [era] considerada definitiva; procura-se sempre aperfeiçoar, melhorar, ampliar. O professor não apresenta aos alunos a solução dos problemas; os alunos pesquisam e trazem seus pontos de vista, que são discutidos pela classe, dentro do maior espírito de colaboração e objetividade. (ibid., p. 55).

Contudo, o principal aspecto que possibilita conectar a experiência do CNF com as Classes Integrais do CEP foi certamente o conhecimento e a difusão do Método de Ensino por Unidades Didáticas, embasado nas teorizações de Henry Morrison. A professora Irene, ao visitar diversas instituições que ainda o adotavam - segundo ela, com relativo sucesso , teve a possibilidade de ampliar seu conhecimento sobre o método resultando, pouco tempo após a viagem, na publicação do livro sobre a experiência de apropriação realizada no CNF. (CARVALHO, 1954). A referência a esse impresso aparece com regular frequência

atividade de visita ao Museu do Louvre para observar "vasos gregos". Não são apresentados mais detalhes sobre em que contexto se deu a visita e tampouco sobre as consequências pedagógicas de tal atividade no plano do curso da instituição, o que deixa em suspenso a profundidade dessa crítica.

12 Vera Muniz (1975) realizou uma pesquisa reunindo inúmeras matérias sobre o CNF em diferentes periódicos desde o início do funcionamento da instituição, tecendo uma narrativa acerca da história e das representações sociais do educandário. 
nos registros das reuniões dos professores do CEP, como é o caso de um dos encontros realizados para a elaboração do projeto das Classes Integrais, datado de 4 de novembro de 1959. Ao abordarem o tema "como orientar as atividades discentes", as seguintes considerações foram indicadas:

\begin{abstract}
inicialmente a orientação das atividades discentes será feita nos moldes do Plano Morrison, em horários prescritos; aos poucos, dependendo do que for sendo observado, poder-se-á passar à distribuição de tarefas quinzenais para dar oportunidade a que cada um trabalhe no seu próprio ritmo, desenvolvendo responsabilidade, etc. (CEP, 1959, grifos do autor).
\end{abstract}

Um roteiro de trabalho foi anexado a essa ata, sistematizando alguns elementos conceituais sobre as "unidades didáticas", além de orientações referentes à motivação dos alunos, às formas de apresentação da matéria, à direção das atividades, às formas de verificação da aprendizagem, entre outros aspectos. Para cada um desses tópicos, são apresentados como referências de leitura e aprofundamento exemplos de atividades ou capítulos e subcapítulos específicos tanto do livro de Irene Carvalho (op. cit.), quanto de outra obra de relativa circulação à época, de autoria de Luiz Alves de Mattos: o livro Sumário de Didática Geral (1957). Outro livro citado, embora com menor frequência, é o Didática Geral (1958) de Onofre de Arruda Penteado Junior. Percebemos nesses indícios o endereçamento do referencial teórico que embasou parte das orientações pedagógicas direcionado a professores das cadeiras de Didática da Universidade do Brasil (RJ) e da Universidade de São Paulo, respectivamente. É possível sugerir que estas obras também fundamentassem os trabalhos da professora Ruth Compiani e de outros professores na Universidade do Paraná, especialmente os que atuavam nas cadeiras de Didática Geral e Didática Especial, sendo os seus usos estendidos, ao que tudo indica, às atividades de orientação nas Classes Integrais do CEP. Essa aproximação entre a Universidade do Paraná e o CEP dá contornos ao segundo grupo de referenciais para as Classes Integrais: os Colégios de Aplicação das Faculdades de Filosofia.

\title{
Aproximações com a Universidade do Paraná: o Colégio Estadual do Paraná como cenário para as experimentações pedagógicas
}

São constantes nos documentos da inovação paranaense as indicações aos Colégios de Aplicação da Universidade de São Paulo e da Universidade do Rio Grande do Sul como referências para a elaboração do plano das Classes Integrais. Mas quais foram os motivos para o endereçamento a essas duas instituições oficiais? Primeiramente, uma justificativa plausível deve-se ao fato de que era recomendação das instruções para a instalação das Classes Experimentais que as inovações fossem desenvolvidas em instituições de "idoneidade incontestável" e com condições pedagógicas que possibilitassem a experiência - nominalmente estavam indicados o Colégio Pedro II (que, registre-se, não aderiu à proposta das Classes Experimentais!) e os Colégios de Aplicação das Faculdades de Filosofia. (MEC, 1958). Logo, a referência a instituições dessa natureza em uma proposta submetida às autoridades e visando à aprovação era, no mínimo, prudente.

Um segundo ponto de conexão com as instituições mencionadas está relacionado à produção e à circulação de impressos específicos daquelas localidades, como os livros 
dos professores da Universidade de São Paulo e, principalmente, os periódicos educacionais - Revista de Pedagogia, de São Paulo e da Revista do Ensino do Rio Grande do Sul - que circularam com relativa frequência entre os professores do CEP. Essa afirmação ganha sustentação pelo fato de serem localizados diversos artigos utilizados nas reuniões entre os professores das Classes Integrais, especialmente para fundamentar 0 estudo e debate de temas relacionados às questões didáticas e de ordem comportamental dos alunos ${ }^{13}$.

Porém, há outro fator que parece ter, para além do aspecto legal/institucional, mais consistência na indicação das inspirações nos Colégios de Aplicação e está relacionado ao papel do CEP no cenário educacional paranaense daquele contexto. Muito embora não se constituísse oficialmente como um Colégio de Aplicação, em agosto de 1956 um acordo entre a Secretaria de Estado da Educação e Cultura e a Reitoria da Universidade do Paraná foi firmado para permitir "que os alunos-mestres que, naquele ano frequentavam o curso de Didática Geral e Especial, pudessem cumprir a Lei n. 9.053, de 12 de março de $1946^{14}$, no que se refere à prática docente real". (CEP, 1957, p. 3). A coordenação das atividades e a articulação dos docentes das duas instituições foram mediadas pelo professor Albano Woiski, que além de professor da UP também ocupava os cargos de professor de Filosofia e orientador educacional no CEP. Dessa forma, em 1957 foi desenvolvido em caráter pioneiro, experimental e temporário "um 'pequeno colégio' dentro do enorme Colégio Estadual do Paraná": o chamado Colégio Experimental anexo ao Colégio Estadual do Paraná. (ibid.).

A idealização da iniciativa teria nascido de duas "observações psicopedagógicas" realizadas ao longo do ano letivo de 1956: "a imperiosa necessidade de um ambiente pedagógico restrito" para a "aplicação didática sob a forma de estágio docente" e a "necessidade de um campo de pesquisas educacionais mais limitado", uma vez que "era de todo impossível de ser realizada 'in massa', em virtude das condições de precariedade do próprio organismo orientador", quer pela falta de "pessoal técnico", quer pela ausência de um "ambiente restrito para o controle" dentro do CEP. Com a organização do Colégio Experimental, estariam criadas condições para observar e pesquisar "as falhas existentes", além de projetar realizações "no sentido de colocar o Colégio Estadual do Paraná na linha das renovações apresentadas pela Escola do século vinte, em moldes mais consentâneos com a época que atravessamos e com os avanços da Psicopedagogia Contemporânea" (ibid.). São perceptíveis os elementos do ideário experimentador: a intensificação dos usos dos conhecimentos das "ciências da educação" e a necessidade da criação de condições de sua aplicação em situações controladas, facilitando a coleta das informações, a interpretação dos resultados e a definição de ações a fim de corrigir as "falhas" identificadas no processo educativo.

Em linhas gerais, o Colégio Experimental funcionou da seguinte forma: dentro do universo de quase 4000 alunos que frequentavam o CEP nos 3 turnos - o que era considerado um "ambiente pedagógico fundamentalmente desconhecido quanto as suas

\footnotetext{
${ }^{13}$ Existem também, embora menos frequentes, indicações de artigos da Revista Curriculum, organizada pelos professores do Colégio Nova Friburgo da FGV, sinalizando a existência de uma rede ampla de periódicos utilizados como subsídios para o trabalho docente no CEP.

14 Referência ao Decreto-Lei 9.053, de 12 de março de 1946 que instituiu a criação de "um ginásio de aplicação nas Faculdades de Filosofia do País", destinado à prática docente dos alunos matriculados no curso de Didática.
} 
reais possibilidades bem como quanto as suas falhas" - foram selecionadas 10 turmas, uma de cada série dos cursos do período matutino, para o controle experimental, "perfazendo no máximo 350 alunos". Para a regência destas turmas foram indicados professores "do próprio corpo docente" do CEP e que estivessem dispostos a colaborar com o trabalho experimental e em receber os alunos-mestres da Universidade do Paraná para realizar as suas práticas de docência. A coordenação geral do trabalho ficou com o professor Woiski, que contou com o apoio da professora Nelly Mattos Mehl, no setor da Psicotécnica e de Ruth Compiani, na Psicopedagogia. No relatório, Woiski ainda menciona a colaboração do "Departamento de Educação Física, Desportos e Recreação Dirigida" do CEP, dirigido por Germano Bayer, na coleta e verificação de alguns resultados. Por fim, há o destaque ao auxílio de 14 alunas ${ }^{15}$ do "curso de Didática" da "seção" de Pedagogia da UP que, além de realizarem suas "práticas didáticas próprias do curso superior que estavam a terminar", auxiliaram com a "aplicação de testes, com a aplicação de provas pedagógicas, questionários, confecção de gráficos, cálculos estatísticos e avaliação de provas psicotécnicas". (ibid., p. 6).

O relatório indica a realização de "exames sociométricos" - considerados "necessidade pedagógica elementar" para quem lidava com "agrupamentos humanos" - a fim de observar "líderes, liderados e marginais" em cada uma das turmas do Colégio Experimental e redirecionar os trabalhos cotidianos a partir desses resultados. Além disso, foi realizado um "inquérito pedagógico" para identificar questões referentes à satisfação dos alunos com a experiência, dificuldades de estudos em disciplinas específicas, alternativas para melhorar o rendimento escolar e sugestões para o aperfeiçoamento da proposta experimental. Por fim, ainda foram realizados testes para "conhecer o aluno" quanto a sua "capacidade física, psicomotricidade, nível mental, idade mental e coeficiente intelectual, escolaridade, caráter e personalidade". (ibid., p. 22) ${ }^{16}$.

Contudo, apesar do número considerável de avaliações aplicadas, o relatório indica que, "pela carência de recursos de pessoal especializado", a única seção que conseguiu produzir algum resultado mais concreto foi a "Divisão de Psicologia" com a sondagem da "situação dos alunos do Colégio Experimental através dos testes da Psicologia Experimental Moderna”. (ibid.). Esta divisão conseguiu tais resultados por escolher, dentre as 10 turmas que compunham o Colégio Experimental, apenas uma para servir de "turmapiloto"17, sendo possível aplicar os testes e realizar os estudos decorrentes das informações obtidas.

Outra particularidade decorrente das atividades cotidianas e que teve relativo impacto na experiência foi relacionada à participação dos professores, indicados pela

\footnotetext{
15 Do conjunto de alunas participantes da iniciativa, cabe o destaque a Odete Schruber, que anos mais tarde viria integrar a equipe de coordenação das Classes Integrais do CEP, ao lado de Ruth Compiani e Esther Holzmann.

16 Uma questão importante: vários dos testes aplicados no Colégio Experimental foram utilizados, anos mais tarde, como expediente comum dos trabalhos nas Classes Integrais, como por exemplo, o Teste das Matrizes Progressivas, de J. C. Raven e o Teste de Inteligência Não Verbal de Pierre Weil. Alguns testes físicos aplicados pelo professor Germano Bayer também continuaram a fazer parte das avaliações.

17 A turma escolhida foi a $1^{\text {a }}$ série do ciclo ginasial, formada "totalmente de meninos [34], cujas idades oscilavam entre 10 anos e meio e 13 anos". Havia a intenção de desenvolver com esta turma "novos métodos pedagógicos, disciplinares e de orientação educacional e vocacional, com vistas ao ajustamento do indivíduo com ele próprio e dele com o meio social onde vive e viverá após o período de curso secundário". (CEP, 1957, p. 21).
} 
direção do CEP para compor o quadro de colaboradores. Albano Woiski ressaltou no relatório que os propósitos do Colégio Experimental

não foram correspondidos por alguns professores que, talvez, não entendendo o que deles era exigido pelas circunstâncias especialíssimas, não somente impediram como (o que foi muito pior), procuraram terminar com as pesquisas, dizendo alto e bom tom que "não estavam ali para servirem de cobaias para a Faculdade de Filosofia". [...] Em virtude de tais falhas, muito do nosso trabalho ficou pelo meio, tantos foram os entraves, os obstáculos, as incompreensões e até má vontade de alguns docentes, que trabalhando em ambiente controlado, agiram sempre dentro da mais infrene rotina de "moer aulas", de "ditar pontos". (CEP, 1957, p. 14).

Como forma de avaliação, embora destaque a potencialidade de muitas das proposições anunciadas, o relatório sugere que as atividades do Colégio Experimental foram realizadas de forma descontínua e lacunar, ficando aquém das expectativas iniciais. Cabe o registro de que, anos mais tarde, muitos dos professores e professoras envolvidos com essa experimentação compuseram a equipe responsável pelas Classes Integrais do CEP. É possível perceber que esse grupo procurou incorporar à inovação dos anos 1960 um conjunto significativo de práticas adotadas na experiência anterior, assim como buscou adotar medidas para corrigir as questões consideradas falhas ${ }^{18}$. Tais práticas estavam conectadas com o terceiro grupo de experiências educacionais que serviram de inspiração para a elaboração do plano das Classes Integrais: as denominadas classes nouvelles francesas.

\section{As Classes Integrais e as apropriações das classes nouvelles: trajetórias peculiares}

A experiência das classes nouvelles surgiu como resultado do debate acerca de uma "reforma radical da educação francesa" necessária em um contexto pós- $2^{a}$ Guerra Mundial, no qual apostava-se no papel a ser desempenhado pela escola "num futuro de paz, com o restabelecimento dos valores democráticos, diante de novas necessidades e dificuldades criadas durante e depois do conflito mundial". (WEREBE, 1956, p. 57). As transformações na vida econômica, social, política e cultural daqueles anos tornaram necessária uma reforma educacional que procurasse atender às novas necessidades do país (ibid., p. 57-58). Foi como uma das realizações do projeto de Reforma LangevinWallon ${ }^{19}$ que as classes nouvelles foram implementadas a partir de 1945 tendo como objetivos "estabelecer princípios e métodos educacionais novos, adaptados à mentalidade e às condições do povo francês". (ibid., p. 58).

O contato in loco com a iniciativa francesa e seus desdobramentos - e o caminho inverso, com a presença de representantes franceses no Brasil para a divulgação dos

\footnotetext{
18 Uma dessas medidas foi a definição de um perfil docente que estivesse disposto a desempenhar as novas atribuições pedagógicas a serem implementadas; outra medida foi a tentativa de organização de classes com menor número de alunos a fim de realizar o acompanhamento individualizado com maior eficiência; por fim, uma ação de destaque foi a adoção da nomenclatura "Classes Integrais" ao invés de "Classes Experimentais", a fim de evitar os "inconvenientes" que a nomenclatura que remete à experiência - e que portanto, "poderia falhar" - poderia causar aos pais dos alunos.

19 Gildásio Amado, em relatório apresentado ao Ministro da Educação e Cultura sobre sua incursão na Inglaterra e na França, em 1953, apesenta uma síntese dos pontos fundamentais dessa reforma, destacando os princípios de "igualdade de todos em face da educação" e "da orientação escolar e vocacional" que direcionavam a proposta. Mais informações, ver RBEP (1955).
} 
trabalhos desenvolvidos - foram realizados por diferentes sujeitos, em distintos momentos ao longo da década de 1950, o que promoveu movimentos diversos de apropriação da experiência em território brasileiro. É possível atribuir à figura do professor Luis Contier ${ }^{20}$ certo pioneirismo no desenvolvimento de elementos da proposta francesa na instituição que ele dirigia - Instituto de Educação Professor Alberto Conte -, muito embora tenha ficado restrito, num primeiro momento, apenas na introdução da "metodologia ativa", desenvolvendo a "iniciativa dos alunos" com a realização de trabalhos com pesquisa, trabalhos em grupo e atividades de Estudo do Meio, conforme identificou Letícia Vieira. Segundo a autora, mesmo com dificuldades estruturais e escassez de corpo docente para implementar a proposta, ainda foi possível incluir o atendimento aos pais dos alunos, como prática ordinária a fim de fortalecer o vínculo da escola com a família. (2015, p. 70).

A circulação em território brasileiro das experiências desenvolvidas na inovação francesa também foi intermediada por Gildásio Amado que, ao ocupar cargos administrativos nos órgãos ligados ao ensino secundário, teve relativo destaque no meio educacional. Em 1953, antes mesmo de assumir a Dese, Gildásio realizou uma viagem para acompanhar as reformas da educação "em estudo ou já em execução" na Inglaterra e na França. Ao retornar, apresentou um relatório ao Ministro da Educação e Cultura, Cândido Mota Filho, no qual encontramos as seguintes considerações sobre as classes nouvelles francesas:

Criadas em 1945 [...] por uma circular da Diretoria do Ensino Secundário, tinham um duplo objetivo: satisfazer, de modo mais perfeito, à função da orientação escolar, e dar aos professores melhores condições de trabalho que permitissem desempenhar a sua tarefa de modo mais adequado às exigências da vida e da cultura moderna. (RBEP, 1955, p. 170).

Avaliadas por Gildásio como "realização efetiva, no sentido da renovação pedagógica" e influenciada por ideais escolanovistas, as classes nouvelles promoveram poucas transformações no âmbito curricular. Segundo ele, o currículo dessas classes compreendia

\begin{abstract}
um núcleo de matérias comuns a todos: francês, história e geografia, uma língua viva, ensino científico (matemática e ciências naturais); e atividades práticas e artísticas, além de educação física e esportiva; algumas destas atividades comportavam um horário obrigatório e um complemento facultativo (desenho, música, trabalhos manuais). Compreendia também opções. Nas duas primeiras séries, o latim era a única opção; na terceira e quarta, além do latim, a música, desenho, estudo do meio social, estudo da natureza, trabalhos manuais. Acentuavase o caráter educativo dos trabalhos manuais, de formação geral mais que de iniciação profissional. (AMADO, 1973, p. 40).
\end{abstract}

As principais inovações consistiram, em síntese, no plano das "normas pedagógicas": classes de 25 alunos, redução na primeira e segunda série do número de

20 Professor paulista nascido em 1915, com formação em línguas neolatinas na Universidade de São Paulo, atuou como professor de Latim, Português e Francês no ensino secundário público e particular em São Paulo a partir de 1941. Em 1948 assumiu o cargo de Diretor do Ensino Secundário e foi nomeado para dirigir o Instituto de Educação Professor Alberto Conte, na capital paulista. Conforme indica Letícia Vieira (2015), em 1950 Contier compôs o primeiro grupo de professores brasileiros a realizar estágio no Centro Internacional de Estudos Pedagógicos de Sèvres. Nos quase dois anos de estágio, conheceu a proposta das classes nouvelles e, tão logo retornou ao Brasil, procurou desenvolver no Instituto Alberto Conte algumas das inovações educacionais observadas no modelo francês. 
professores, instituição de uma hora semanal de conselho de classe, coordenação das diversas matérias e atividades, métodos ativos, individualização do ensino, estímulo a trabalho em equipe. (ibid.). A partir de 1952, em virtude das restrições orçamentárias - e também de alguns resultados pouco satisfatórios atingidos -, ocorreu a "recondução da experiência" e as classes passaram a ser denominadas classes pilotes, sendo mantidas em funcionamento em 60 instituições. (WEREBE, op. cit., p. 58). Em linhas gerais, com o amadurecimento da proposta ao longo dos anos, esperava-se das renovadas classes a manutenção do "espírito das classes nouvelles, seus métodos, a vontade de pesquisa e de progresso que as anima" a fim de "penetrar progressivamente em todo o ensino de segundo grau francês". (CIEP, s/d, p. 2, tradução nossa).

A presença em solo brasileiro de educadores franceses ligados às classes nouvelles também precisa ser destacada. Destes, talvez a contribuição mais significativa tenha sido por intermédio das atividades desenvolvidas por Mme. Edmée Hatinguais para a divulgação da pedagogia adotada nas classes francesas ${ }^{21}$. Inspetora Geral da Educação Pública na França e primeira Diretora do Centre International d'Études Pedagógiques (Ciep), esteve no Brasil, primeiramente, em 1954 a convite do governo federal, para a realização de palestra a "respeito da relação escola-família na formação dos jovens", em São Paulo. (MARQUES, 1985, p. 31). Há registros da realização de outras conferências sobre as reformas e o contexto educacional francês, destacadas com certo entusiasmo por Maria José Werebe (1956) e que, inclusive, resultou no artigo publicado na Revista de Pedagogia da USP no qual a educadora paulista apresenta elementos estruturantes da "renovação pedagógica" em curso na França daquele contexto.

Com relação à especificidade das Classes Integrais do Colégio Estadual do Paraná, podemos identificar que outras mediações resultaram no conhecimento das atividades desenvolvidas no Ciep de Sèvres. A professora Ruth Compiani teve contato com as inovações das classes nouvelles por meio de um artigo de Edna Chagas Cruz, professora auxiliar da cadeira de Didática Geral e Especial da USP, publicado na Revista de Pedagogia daquela instituição. No relato dos cinco meses de estágio no Ciep, realizado no início de 1959, a docente paulista apresentou um "traçado esquemático dos métodos ativos nas classes experimentais de Sèvres" (1959, p. 19) mesclando as suas observações com a tradução do material de divulgação do Ciep (s/d), guardando muitas semelhanças com os principais elementos estruturantes do plano das Classes Integrais.

$\mathrm{O}$ acesso às fontes permite sugerir que, além do conhecimento da proposta francesa via Revista de Pedagogia, outros sujeitos que participaram da elaboração do projeto das Classes Integrais estiveram em contato com apropriações do modelo pedagógico das classes nouvelles desenvolvidas em localidades distintas. É o caso, por exemplo, do professor de Educação Física, Germano Bayer. A trajetória do professor paranaense tem em comum, com Gildásio Amado, a participação em um evento em Santiago (Chile) e guarda algumas particularidades nesse sentido. Segundo Germano, em 1956, durante a realização do Congresso Pan-americano de Educação Física sediado na

21 Ângela Tamberlini (2001) indica que as palestras realizadas tiveram, à época, pouca repercussão; versão que tem alguma reverberação entre as pesquisas sobre a temática. Contudo, Mme. Hatinguais esteve no Brasil em mais algumas oportunidades, como em 1961 para divulgar o "êxito das classes nouvelles e estudando as condições para a vinda de uma missão francesa destinada a preparar professores para o uso de novos métodos e técnicas do ensino" (MARQUES, 1985, p. 31), criando um "elo entre o CIEP e os educadores brasileiros". (STEINDEL; DALLABRIDA; ARAUJO, 2013). 
capital chilena, os participantes tiveram a oportunidade de conhecer os trabalhos desenvolvidos no Liceo Experimental Manuel de Salas. (2010, p. 279). Na ocasião, afirma Germano, tanto ele quanto Gildásio Amado ${ }^{22}$ ficaram impactados com os trabalhos observados e consideraram que a experiência chilena, baseada nas classes nouvelles e desenvolvida num contexto diferente do francês, poderia ser uma potencial inspiração para suas atuações profissionais no Brasil.

Ao procurar informações sobre a instituição chilena, foi possível identificá-la como referência quanto às inovações educacionais sendo reconhecida por se constituir, de acordo com Jaime Caiceo Escudero (2010, p. 110), um "laboratório pedagógico destinado à aplicação e experimentação de novas organizações, métodos e programas de ensino secundário" desde sua fundação, em 1932. O autor também destaca o papel de Irma Salas na direção do Liceo, entre 1933 e 1943, ressaltando que a educadora chilena, quando realizou seus estudos de doutorado nos Estados Unidos, na Universidade de Columbia, teve contato direto com John Dewey e William Kilpatrick. Esta etapa da formação da professora Irma marcou fortemente as suas atuações no retorno ao Chile, quando teve participação ativa nas reformas de ensino encampadas pelo Ministério da Educação, com a formação de professores na Universidad de Chile e na atuação em órgãos internacionais, por exemplo, como Especialista Permanente da Educação da Unesco. Por sua vez, Florencia Barrios Tirado (2014) afirma que o Liceo Manuel de Salas desenvolveu uma "filosofia educacional" baseada em princípios que garantiriam a melhor convivência em uma "sociedade democrática, permitindo aos indivíduos, junto com o exercício da liberdade e de seus direitos, desenvolver sua personalidade a fim de cumprir suas responsabilidades frente à coletividade nacional". Além disso, os princípios indicados na proposta consideravam a educação como um processo que capacitaria o indivíduo para "adaptar-se ao meio em que vive, interpretando-o e melhorando-o". (TIRADO, 2014, p. 310).

O ponto de conexão da inovação chilena com os trabalhos desenvolvidos nas Classes Integrais ganha nitidez ao identificarmos nos afazeres de Germano Bayer a referência ao chamado "Plano Variável" do Liceo Manuel de Salas, destacando a existência de "escolas em que as atividades extraclasse já se incorporaram definitivamente no currículo escolar". (COMPIANI, 1961, s. p.). Este é um indício importante que permite articular a circulação de Germano pela instituição chilena, anos antes, com algumas das questões incorporadas na elaboração da proposta das Classes Integrais ${ }^{23}$.

\section{Considerações finais}

Estes foram, em linhas gerais, os "pontos de partida" utilizados como referências para a elaboração do Plano de Organização das Classes Integrais, implementado a partir

\footnotetext{
${ }^{22}$ Esta é uma questão importante: embora Germano Bayer pondere que a experiência desenvolvida no Chile tenha causado repercussões em Gildásio Amado, esta afirmação não foi localizada na trajetória de Gildásio. O que ele afirma em suas publicações é que a inspiração para a elaboração da proposta das Classes Experimentais brasileiras teria surgido quando esteve em solo europeu, em 1953, para a missão comissionada de estudos sobre as reformas do ensino na Inglaterra e na França, onde, nesta última, teve contato com diretamente com as classes nouvelles. (AMADO, 1973, p. 40-41). O acesso às fontes permitiu localizar indícios de que Gildásio Amado esteve em contato com propostas desenvolvidas em outras localidades - como é o caso da experiência chilena - e que parecem ter contribuído para a elaboração da proposta das Classes Experimentais.

${ }^{23}$ Questões específicas sobre o trabalho de Germano Bayer nas Classes Integrais podem ser encontradas em Chaves Jr. (2017).
} 
de 1960 no Colégio Estadual do Paraná. Com a apresentação desse conjunto de iniciativas foi possível identificar os endereçamentos nos quais os elaboradores do plano das Classes Integrais do CEP buscaram "inspiração", o que resultou em uma proposta que guardava semelhanças com as demais inovações, mas também, em virtude das apropriações diversas e das características próprias da instituição de ensino, do corpo docente e do contexto no qual foi desenvolvido, constituiu um arranjo muito particular no conjunto das experimentações educacionais do ensino secundário nos finais dos 1950.

Esse processo ativo de apropriação e de ressignificação de propostas com concepções e matrizes teóricas distintas deu contornos à experiência das Classes Integrais. Procurei demonstrar que, ao pensarmos em termos de circulação de ideias e modelos pedagógicos, devemos levar em conta sua dinâmica múltipla e complexa, e não apenas a simples difusão, reprodução ou "transplantação" de modelos de um contexto a outro. Nesse sentido, é importante destacar que aquilo que circula não é uma entidade desencarnada, constituída em si mesma, de maneira desconectada dos agentes de mediação cultural. Em outros termos, sempre há envolvimento de pessoas, de instituições ou de suportes materiais que promovem o encontro entre culturas, de acordo com interesses, demandas e circunstâncias específicas. (GRUZINSKI, 2001; FONSECA, 2012).

Por fim, é preciso situar que a iniciativa paranaense, assim como as demais que atenderam pelo nome Classes Experimentais, foram representantes de um movimento em escala nacional - embora com limitado alcance no que se refere ao número de instituições e de estudantes secundaristas atendidos - oportunizado pela publicação das "Instruções sobre a natureza e a organização das classes experimentais", as quais incentivaram o "[ensaio e] aplicação de novos métodos pedagógicos e processos escolares, bem como de tipos de currículo compatíveis com a atual legislação do ensino médio". (RBEP, 1958, p. 80). O desenvolvimento dessas iniciativas sinaliza para a legitimação do ideário experimentador como "recurso para introduzir algumas inovações" naquele regime estritamente contido, conforme interpretou Gildásio Amado (1973, p. 50), ao ponderar sobre o cenário no qual foi construída a Lei de Diretrizes e Bases de $1961^{24}$. Contudo, o avançar para tais questões demandam análises que extrapolam os limites deste texto.

\section{Referências}

AMADO, Gildásio. Educação Média e Fundamental. Rio de Janeiro: Livraria José Olympio Editora; Brasília: Instituto Nacional do Livro/MEC, 1973.

BARRIOS TIRADO, Florencia. El Liceo Experimental Manuel de Salas: un aporte de la Universidad de Chile a la educación nacional [1983]. Anales de la Universidad de Chile. [S.I.], serie 7, n. 7, p. 307-337, nov. 2014. Disponível em: <http://www.anales.uchile.cl/index.php/ANUC/article/view/35906/37552>. Acesso em: 17 fev. 2018.

BAYER, Germano. Ser professor de Educação Física. Blumenau: Nova Letra, 2010.

24 Importante destacar que as possibilidades de flexibilização inicialmente garantidas por meio dessa autorização de funcionamento de Classes Experimentais, foram mantidas e ampliadas naquela LDB. De acordo com o Art. 104, "Será permitida a organização de cursos ou escolas experimentais, com currículos, métodos e períodos escolares próprios, dependendo o seu funcionamento para fins de validade legal da autorização do Conselho Estadual de Educação, quando se tratar de cursos primários e médios, e do Conselho Federal de Educação, quando de cursos superiores ou de estabelecimentos de ensino primário e médio sob a jurisdição do Governo Federal". (BRASIL, 1961). 
BRASIL. Ensino secundário no Brasil: organização, legislação vigente, programas. Rio de Janeiro: INEP, 1952.

Lei n. 4.024, de 20 de dezembro de 1961. Fixa as Diretrizes e Bases da Educação Nacional.

CAICEO ESCUDERO, Jaime. Amanda Labarca, Irma Salas y Mabel Condemarín, tres educadoras laicas y feministas del siglo XX en Chile. Revista Teoria e Prática da Educação, Maringá, v. 13, n. 1, p. 105-116, jan./abr. 2010.

CARVALHO, Irene da Silva Mello. Alguns aspectos da educação secundária norteamericana. Revista Brasileira de Estudos Pedagógicos, Rio de Janeiro, v. 20, n. 51, p. 45-58, jul./set. 1953b.

O ensino por unidades didáticas. 4 ed. Rio de Janeiro: FGV, 1969.

O ensino por unidades didáticas: seu ensaio no Colégio Nova Friburgo. Campanha de Inquéritos e Levantamentos do Ensino Médio e Elementar - publicação n. 4. Rio de Janeiro: MEC/Inep/Cileme, 1954.

Relatório da viagem de estudos aos Estados Unidos da América do Norte. Rio de Janeiro: Departamento de Ensino, Fundação Getúlio Vargas, 1953a. Núcleo de Documentação da Fundação Getúlio Vargas.

Relatório de viagem à Europa. Rio de Janeiro: Departamento de Ensino, Fundação Getúlio Vargas, 1952. Núcleo de Documentação da Fundação Getúlio Vargas.

CENTRE INTERNATIONAL D'ÉTUDES PEDAGÓGIQUES (CIEP). Classes Nouvelles / Classes Pilotes. Sèvres: Centre International d'Études Pedagógiques. [s/d]. Arquivo Luis Contier: Centro de Memória da Faculdade de Educação da USP.

CHAVES JR., Sérgio Roberto. "Um embrião de laboratório de Pedagogia": as Classes Integrais do Colégio Estadual do Paraná no contexto das inovações pedagógicas no ensino secundário (1960-1967). 2017. 270 f. Tese (Doutorado em Educação) - Programa de Pós-Graduação em Educação: Conhecimento e Inclusão Social, Faculdade de Educação, Universidade Federal de Minas Gerais, Belo Horizonte, 2017.

CHIOZZINI, Daniel Ferraz. História \& Memória da inovação educacional no Brasil: o caso dos Ginásios Vocacionais (1961-1970). Curitiba: Appris, 2014.

COLÉGIO ESTADUAL DO PARANÁ (CEP). Classes Integrais (Experimentais) do Colégio Estadual do Paraná. Histórico. Curitiba. 1963. Acervo pessoal de Ruth Compiani.

Classes Integrais do Colégio Estadual do Paraná. Curitiba. [1967?]. Acervo pessoal de Ruth Compiani.

Colégio Experimental do Colégio Estadual do Paraná. Primeiro relatório referente às suas atividades. Curitiba. 1957. Acervo do Arquivo Geral do Colégio Estadual do Paraná.

Plano de Organização das Classes Experimentais. Primeiro ciclo. Curso secundário. Curitiba. 1960. Acervo pessoal de Ruth Compiani.

Reunião do dia 4 de novembro de 1959. Ata da reunião do corpo docente das Classes Experimentais. 1959. Acervo do Arquivo Geral do Colégio Estadual do Paraná.

COMPIANI, Ruth. Atividades Extraclasse: Encontro de Diretores de Escolas

Secundárias. Relatório. Promoção DESe/Cades-Seccional de Curitiba. Irati, 1961. Acervo pessoal de Ruth Compiani.

CRUZ, Edna Chagas. Os métodos ativos nas Classes Experimentais do Liceu de Sèvres. 
Revista de Pedagogia, São Paulo, ano V, v. V, n. 9, p. 19-29, jan./jun. 1959.

CUNHA, Nádia; ABREU, Jayme. Classes Secundárias Experimentais: balanço de uma experiência. Revista Brasileira de Estudos Pedagógicos, Rio de Janeiro, v. 40, n. 91, p. 90-151, jul./set. 1963.

FERRETTI, Celso João. A inovação na perspectiva pedagógica. In: GARCIA, Walter (Org.). Inovação educacional no Brasil: problemas e perspectivas. São Paulo: Cortez Editora, Autores Associados, 1980. p. 55-82.

FONSECA, Thais Nivia de Lima e. Mestiçagem e mediadores culturais e história da educação: contribuições da obra de Serge Gruzinski. In: LOPES, Eliane Marta Teixeira; FARIA FILHO, Luciano Mendes (Orgs.). Pensadores sociais e história da educação. v. 2. Belo Horizonte: Autêntica, 2012.

GOMES, Ângela de Castro (Coord.). Olhando para dentro: 1930-1964. Rio de Janeiro: Objetiva, 2013.

GRENDI, Edoardo. Repensar a micro-história? In: REVEL, Jacques (Org.). Jogos de Escalas: a experiência da microanálise. Rio de Janeiro: Editora da Fundação Getúlio Vargas, 1998.

GRUZINSKI, Serge. O pensamento mestiço. São Paulo: Companhia das Letras, 2001.

KANDEL, Isaac Leon. O estudo da educação comparada. Revista Brasileira de Estudos Pedagógicos, Rio de Janeiro, v. 25, n. 62, p. 28-40, abr./jun. 1956.

LIMA, Henrique Espada. A micro-história italiana. Escalas, indícios e singularidades. Rio de Janeiro: Civilização Brasileira, 2006.

LOPES, Luiz Simões. Apresentação. Curriculum, Rio de Janeiro, v. 1, n. 1, 1ำ sem., p. 56, 1962.

MARQUES, Sandra Machado Lunardi. Contribuição ao estudo dos Ginásios Vocacionais do Estado de São Paulo: o Ginásio Vocacional "Chanceler Raul Fernandes” de Rio Claro. 1985. 407 f. Dissertação (Mestrado em Educação) - Pontifícia Universidade Católica de São Paulo, São Paulo, 1985.

MATTOS, Luiz Alves de. Sumário de Didática Geral. Rio de Janeiro: Aurora, 1957. MINISTÉRIO DA EDUCAÇÃO E CULTURA (MEC). Instruções sobre a natureza e a organização das classes experimentais. Revista Brasileira de Estudos Pedagógicos, Rio de Janeiro, v. 30, n. 72, p. 73-83, out./dez. 1958.

MUNIZ, Vera Pereira. A história do Colégio Nova Friburgo através de referências pela Imprensa. Curriculum, Rio de Janeiro, v. 14, n. 1, p. 18-58, jan./mar. 1975.

PARANÁ. Lei n. 170, de 14 de dezembro de 1948. Dispõe sobre a organização e atribuições da Secretaria de Educação e Cultura.

PENTEADO JUNIOR, Onofre A. Apresentação. Revista de Pedagogia, São Paulo, ano I, v. 1, n. 1, p. 1, jan./jun. 1955.

Didática geral. São Paulo: Gráfica Cruzeiro, 1958.

REVEL, Jacques (Org.). Jogos de escalas: a experiência da microanálise. Rio de Janeiro: Fundação Getúlio Vargas, 1998.

REVISTA BRASILEIRA DE ESTUDOS PEDAGÓGICOS (RBEP). Classes experimentais no ensino secundário. Revista Brasileira de Estudos Pedagógicos, Rio de Janeiro, v. 30, n. 72, p. 73-83, out./dez. 1958.

Relatório do professor Gildásio Amado sobre as reformas da educação na França 
e na Inglaterra. Revista Brasileira de Estudos Pedagógicos, Rio de Janeiro, v. 24, n. 60, p. 159-197, out./dez. 1955.

ROZANTE, Ellen Lucas. A Revista de Pedagogia da Cadeira de Didática Geral e Especial da Faculdade de Filosofia, Ciências e Letras da Universidade de São Paulo (1955-1967): a formação do professor do ensino secundário. 2008. 97 f. Dissertação (Mestrado em Educação) - Programa de Pós-Graduação em Educação, Pontifícia Universidade Católica de São Paulo, São Paulo, 2008.

SANTOS, Pablo Silva Machado Bispo dos. O Colégio Nova Friburgo da Fundação Getúlio Vargas: mergulhando em sua memória institucional. 2005. 171 f. Dissertação (Mestrado em Educação) - Departamento de Educação, Pontifícia Universidade Católica do Rio de Janeiro, Rio de Janeiro, 2005.

SILVA, Geraldo Bastos. A educação secundária. Perspectiva histórica e teoria. São Paulo: Companhia Editora Nacional, 1969.

SOUZA, Rosa Fátima de. História da organização do trabalho escolar e do currículo no século XX: ensino primário e secundário no Brasil. São Paulo: Cortez, 2008.

STEINDEL, Gisela Eggert; DALLABRIDA, Norberto; ARAUJO, Elisabete Maria de. Gustave Monod e as Classes Nouvelles: apropriações e renovações no ensino secundário francês. In: COLÓQUIO ENSINO MÉDIO, HISTÓRIA E CIDADANIA, 8, 2013, Florianópolis. Anais.... Florianópolis: Udesc/Faed/Grupo de Pesquisa Sociedade, Memória e Educação, 2013. 12 p. Disponível em <http://www.revistas.udesc.br/index.php/EnsinoMedio/index>. Acesso em: 17 fev. 2018.

STRAUBE, Ernani Costa. Do Licêo de Coritiba ao Colégio Estadual do Paraná. Curitiba: Fundepar, 1993.

TAMBERLINI, Ângela Rabello Maciel de Barros. Os ginásios vocacionais: a dimensão política de um projeto pedagógico transformador. São Paulo: Annablume: Fapesp, 2001.

TEIXEIRA, Anísio. A crise educacional brasileira. Revista Brasileira de Estudos

Pedagógicos, Rio de Janeiro, v. 19, n. 50, p. 20-43, abr./jun. 1953.

VIEIRA, Letícia. Um núcleo pioneiro na renovação da educação secundária brasileira: as primeiras classes experimentais do estado de São Paulo (1951-1964). 2015. 200 f. Dissertação (Mestrado em Educação) - Programa de Pós-graduação em Educação, Centro de Ciências Humanas e da Educação, Universidade do Estado de Santa Catarina, Florianópolis, 2015.

WEREBE, Maria José Garcia. A renovação pedagógica em França. Revista de Pedagogia, São Paulo, ano II, v. 2, n. 3, p. 57-68, jan./jun. 1956.

SERGIO ROBERTO CHAVES JUNIOR é professor adjunto da Universidade Federal do Paraná (UFPR), lotado no Departamento de Teoria e Prática de Ensino, Setor de Educação (DTPEN/ED). Possui graduação em Licenciatura em Educação Física pela Universidade Federal do Paraná (2000), Especialização em Educação Física Escolar pela Universidade Federal do Paraná (2003), Mestrado em Educação pela Universidade Federal do Paraná (2004) e Doutorado em Educação pela Universidade Federal de Minas Gerais (2017). Endereço: Rua Paulo Szpak, 53 - sobrado 4, Bairro Uberaba, 81580-180, Curitiba/PR. E-mail: sergiojunior79@hotmail.com 
Recebido em 26 de fevereiro de 2018.

Aceito em 04 de julho de 2018.

(c) (i) 